\title{
DOCUMENTÁRIO
}

\section{NOTAS SÓBRE O CAMINHO PARA MATO GROSSO}

\begin{abstract}
A descoberta do ouro na região de Cuiabá em 1719, ou mesmo antes segundo alguns autores, veio revelar e incorporar ao patrimônio luso-brasileiro em terras americanas extensas regióes às quais logo se atiraram os paulistas intemeratos, devassadores audazes dos sertões, levando a marca de sua expansão até o mais longínquo centro-oeste, com a fundação, nas margens do Guaporé, da primitiva Vila-Bela, posteriormente Mato Grosso, a "cidade do ouro e das ruínas". O desastre sofrido pelos paulistas em Minas Gerais na guerra dos emboadas (1709) levou-os a procurar outros centros de atividade mineradora, longe da rivalidade e da inveja dos reinóis, sempre prontos a tirarem o melhor partido do trabalho árduo dos intrépidos sertanistas e descobridores de São Paulo. A expansão paulista em Goiaz e Mato Grosso pode ser levada à conta de consequiências principais dêsse desvio no rumo da atividade expansionista. Desnecessário dizer que as mesmas rivalidades e, consequientemente, as mesmas lutas surgiriam bem cêdo em terras matogrossenses, como 0 atestam os cronistas que se ocuparam do assunto nos séculos XVIII e XIX.

Este movimento de expansão para o centro-oeste brasileiro corresponde ao denominado "ciclo das monções", no qual coube a preponderância aos filhos de Sorocaba, tal como no início da mineração em Minas Gerais coubera a preponderância aos filhos de Taubaté. Em nenhuma outra região do território brasileiro foram tão grandes as dificuldades e os obstáculos a vencer por parte dos devassadores paulistas, principalmente na luta contra o indígena, como na regiāo matogrossense. "Afora as cachoeiras e itaipavas, as inundações das caudais na quadra das chuvas, a fome e as febres, as legiōes de insetos incômodos ou nocivos, as serpentes e as feras - foi ali que os índios opuzeram mais b́bices aos destemerosos mamelucos" (1).
\end{abstract}

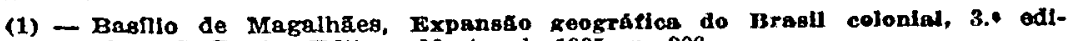
câo. S. Paulo, Editora Nacional, 1035, p. 208. 
Todavia, tão rico se afigurava o novo Pactolo descoberto, que verdadeiro "rush" para tão longínquas terras assinalam as crônicas relativas aos dez primeiros anos após as penetrações de que resultaram as primeras amostras de ouro. "Divulgada a notícia pelos povoados, foi tal o movimento que causou nos ânimos, que das Minas Gerais, Rio de Janeiro e de tôda a capitania de São Paulo se abalaram muitos, deixando casas, fazendas, mulheres e filhos, botando-se para êstes descobertos como se fôra a Terra da Promissão ou o Paraíso em que Deus pôs nossos primeiros pais", no dizer de um dos cronistas cuiabanos dos fins do século XVIII (2).

A elevação de Mato Grosso à categoria de capitania independente da de São Paulo (1748) foi a consequiência política do rápido desenvolvimento daquelas terras, cujo desmembramento marcou o último dos cortes sofrido pelo território paulista no século XVIII, reduzindoo a pouco mais do que as proporções atuais depois de, em sua área, englobarem-se Minas-Gerais, Mato-Grosso, Goiaz e todo o sul do Brasil.

Dos riscos imensos, bem como de tôdas as dificuldades que ofereciam as viagens para Mato-Grosso dão testemunho todos os cronistas e todos os que se ocuparam dêsse movimento. $\mathbf{O}$ citado cronista cuiabano dos fins do século XVIII - Joaquim da Costa Siqueira - referindo-se a uma das expedições do ano de 1720, pinta com côres negras, evidentemente exageradas, as dificuldades aludidas: "Padeceram grandes destroços, perdições de canoas nas cachoeiras por falta de pilotos e práticos, que ainda então não havia, mortandade de gente por falta de mantimentos, doenças, comidas das onças, e outras muitas misérias; não sabiam ainda pescar, nem caçar, nem o uso de toldar as canoas, que tudo lhe aprodrecia com as chuvas, nem também dos mosquiteiros para a defesa dos mosquitos que muitos anos depois foram a experiência e a necessidade ensinando tôdas estas cousas pelo que padeceram de misérias sôbre misérias os que escaparam de morte; houve comboio de canoas em que morreram todos sem ficar um vivo, pois eram achadas as canoas e fazendas podres pelos que vinham atraz, e os corpos mortos pelos redutos e barrancos" (3).

Quase todo o percurso era fluvial, representando o nosso Tietê seu grande papel de via de penetração ainda não suficientemente assinalado em tôda a sua importância. A navegação tinha início em Pôrto Feliz (primitivamente Araraitaguaba), uma vez que $\circ$ trecho do Tietê que antecede aquele pôrto não se presta à navegação pelas inúmeras corredeiras. Do Tietê passavam ao Paraná, descendo êste até encontrarem um dos seus grandes afluentes da margem matogrossense, o Pardo ou o Ivinheima, que remotavam até onde o permitissem as águas. Através dum vara-

(2) - Joaquim da Costa Siqueira, Cronicas do Culabs, in Rev. do Inst. Hist. Geo. S. Paulo, v. IV., D. 19. S. Paulo, 1898-1899.

(8) - Joaquim da Costa Slqueira, op. dit., D. 19. 
douro atingiam os rios da bacia do Paraguai, alcançando por êles a região da mineração. A procura dum varadouro menos extenso foi sempre uma preocupação constante pelas dificuldades imensas que a sua transposição oferecia.

Algumas descrições existem, bem detalhadas, das viagens para Mato Grosso, tôdas elas ressaltando os grandes óbices que oferecia a rota, desde a própria navegação até o risco de ataques das nações indigenas do sul de Mato-Grosso.

O mais antigo dêsses relatos talvez seja o que Afonso de $\mathbf{E}$. Taunay publicou no tomo I dos "Anais do Museu Paulista", "papel do segundo quartel do século XVIII em que ocorrem diversas circunstâncias valiosas para o estudo de bandeirismo", no dizer do erudito historiador das bandeiras paulistas, copiado de manuscrito existente na Biblioteca Nacional e cuja importância foi assinalada por Capistrano de Abreu, segundo o depoimento do próprio Taunay (4).

A seguir, ocorre-nos o "Diário da navegação" de Teotônio José Juzarte, de 1769, também divulgado por Taunay no mesmo volume dos "Anais do Museu Paulista" (5). Parece ser o mais valioso dos documentos que sôbre o assunto nos ficaram do século XVIII. Outro, também importante, é o relato de Manoel Cardoso de Abreu, medíocre escritor paulista do século XVIII do qual longamente se ocupou Taunay em seu livro "Escritores coloniais". Seu trabalho, que traz o gongórico título de "Divertimento admirável para os historiadores observarem as máquinas do mundo reconhecidas nos sertões da navegação das minas de Cuiabá e Mato-Grosso", datado de 1783, foi descoberto e divulgado por Eduardo Prado e oferece mais abundância de informes no que se refere à navegação e a vida nos povoados fundados pelos paulisías em Mato-Grosso (6). Deve ser assinalado, ainda, o relato de Lacerda e Almeida "Diário de Vila-Bela até a cidade de São Paulo pela ordinária derrota dos rios", de 1788-1790 (7) bem como - valioso documento há alguns anos divulgados por Taunay - a carta de um passageiro de monção, datada de 1785 e da lavra do

(4) - Demonetracá dos dereron comlnhos quo os moradores do 8. Paulo so sorvem para os rlos Cuyaba o provincia de cochipone, in "Anais do Museu L'aulista", t. I, 2.0 parte, pp. 455-404. S. Paulo, 1022.

(5) - "Diário da navégaçao do rio Tieté, Rio Grande Paraná, e Rlo e Gatemy em que se dá Rellação de todas as cousas mals notavels destes Rios, seu curso, sua distancia, e de todos os mals Rios, que se encontrão, Ilhas, perigos, e de tudo o acontecido neste Viarlo, pelo tempo de dous annos e dous mezcs. Que principia em 10 de Marco de 1769 . Escrito pelo Sargento. Mor Theotonio Jose Juzarte" in "Anals do Museu P'sulista", t. I, parte II, pp. 41-1.18. S. Paulo, 1922. Relmpresso in "revista do Arquivo Municipal", $\checkmark$ LXI, pp. 77-122. S. Paulo, 1939.

(6) - V. Revista do Inst. Hist. Geogr. S. Paulo, v. VI, pp. 253-290. S. Paulo. 1902 .

(7) - Este relato de Jacerda e Almeida fol incluido no "Diário da Viagem pelas Capitanias do Pará. Rlo Negro, Mato Grosso, Culabá e São Paulo nos anos de 1780 a 1790". Impresso por ordem da Assembleia Legisla. tiva da Provincia de Sāo Paulo. S. Yaulo, Tip. Costa Silveira, 1841. Reedíçāo teita pelo Instituto Nacional do Livro em 1944, com nota-prefácio de Sérgio Buarque de Holanda, reunindo diversos outros trabalhos do grande viajante portugues. 
dr. Diogo de Toledo Lara e Ordonhes, magistrado em Mato-Grosso nos fins do século XVIII (8).

Finalmente aludiremos a um valioso manuscrito da Biblioteca de Evora (Cod. CXVI/2-13, n. ${ }^{0} 18$ ) há pouco divulgado na coleção "Documentos dos arquivos portuguêses que importam ao Brasil", que contém o breve roteiro dos caminhos que no século XVIII os paulistas faziam para penetrar no Cuiabá, obra de autor anônimo, provàvelmente um prático de tão perigosas e dilatadas viagens. $O$ interêsse dêsse pequeno roteiro, aliado à circunstância de ter sido dado à publicidade em Portugal, portanto pouco conhecido entre nós, animou-nos a divulgá-lo:

"Da cidade de São Paulo à villa da Parnayba he hum dia de viagem; quem leva carga gasta 2 dias neste caminho. Da Parnayba à villa de Utû o mesmo. Da de Utû ao porto do rio he huma legoa. De São Paulo athe este lugar não permite o rio navegação, pellos precipicios de suas pedras. De Utû para baxo se ajuntão as canoas, e formadas as frotas partem para varias conquistas. Athe o rio grande gastão 20 dias navegando de pela manhã athe a 2 da tarde. Em duas partes, que chamão Abanhendaba, e Masuira por serem as cacheiras altas levão as canoas por terra estivado o caminho com madeiras. Em outras duas partes pello perigo, tirão as cargas das canoas, e estas vão à sirga. Tem outras correntezas de menos perigo".

E extraordinária a semelhança entre êste manuscrito de Evora e o original da Biblioteca Nacional divulgado por Taunay: as mesmas observações relativas às dificuldades de navegação no Tietê, ao tempo gasto na viagem, à circunstância de só navegarem até as duas horas da tarde, à interrupção nas cachoeiras maiores (Avanhandava, por exemplo).

"Tanto que as frotas chegarão ao rio grande navegão por ele abaixo 6 dias athe a barra do rio Pardo, que the saye da parte da mão direita, e logo sobem por elle a rumo do nordeste per espaço de 23 dias, não sem dificuldade per causa da muita correnteza e pedras. Dexadas as canoas aonde no rio Pardo já não se pode navegar, caminhão os paulistas per terra athe o Cuyaba per espaço de 25 dias, ou hum mez. Outros Paulistas por fogirem o trabalho de caminho de terra tão dilatado, caminhão per terra somente 10 ou 12 dias athe o ribeirão Itikira, ou em outro chamado Piaguy, os quais então

(8) - Taunay, Afonso de E., Assuntos do trés séculos colonials, 1698-1790. S. Paulo, Imprensa oficial, 1844. 
em outro rio mayor chamado Pikiri com navegação de 5 dias. Este rio Pikri entra em outro mayor charado Parrudos, pello qual sobem e em breve navegação chegão a bara do rio Cuyaba, o qual desce dos morros de Cochiponé e he braço principal do rio dos Parrudos, e este crescido já com tantos braços e rios vay dar no grande rio do Paraguay. Outros Paulistas depois de navegarem pello rio Pardo assima, entrão por hum de seos braços chamado Ypiranga, donde atravessando por terra para a parte das vargens achão $\circ$ ribeiro navegavel chamado Camapoan em distancia de 3 legoas; por este ribeyro, que he navegavel descem ao Tacoary, o qual com navegação de 8 dias, entra no rio Paraguary, e sobindo por este assima em distancia de 10 dias de viagem entrão na barra do rio dos Parrudos, da qual barra athe o Cuyaba são 20 dias de viagem. No anno passado Lourenço Leme levou por terra huma canoa feita em Utû e do braço Ypiranga apassou ao Campoã e foy por este caminho ao Cuyaba".

A navegação do rio $P a r d o$ foi, de fato, a mais utilizada na rota para Mato-Grosso, embora a do Ivinheima não fôsse de todo de prezada. Ponto de referência importante é o varadouro de Camapoã, pelo qual alcançavam o rio Coxim e por êste o Taquarí, o Pá. raguai e o Cuiabá. Ali se abriu logo um centro de povoamento a Fazenda do Camapoã, "única que se acha em tão dilatado sertão, estabelecida por necessidade por causa da varação das canoas", segundo o depoimento do dr. Ordonhes na carta a que nos referimos, "fundada no centro dêste sertão sòmente com o fim de ter carros prontos para a varação das canoas e cargas de um para o outro rio", segundo o dizer de Lacerda. Sôbre as dificuldades de transposição dêsses varadouros escreveu o autor do "Divertimento admirável": "As canoas são conduzidas em carros muito grandes, de 4 rodas, puxados por 6,8 juntas de bois. As cargas pesadas vão em outros de duas rodas e as mais medianas vão às costas dos negros, que puxam as mesmas canoas, saindo daquele lugar para a fazenda à meia noite, acompanhados de outras pessôas que vão alugadas para o serviço da viagem, com armas de fogo para a guarda e defesa dos mesmos negros, os quais não indo com esta precaução é infalível - serem feridos do mesmo caiapó, que não cessam as suas traições em semelhantes lugares" (9).

"Os Paulistas que vão pela vacaria, tanto que no rio grande chegarão à barra do rio descem mais 4 dias pello mesmo rio grande athe o rio Imonheyma, o qual per 3 braços entra no dito rio grande. $O$ braço per onde entrão os Paulistas chamasse Ainhanguepy. Navegão pello dito

(9) - Rev. Inst. Hist. Geogr. S. Paulo, VI, 267. Sũo Paulo, 1902. 
Imonheyma assim per espaço de 18 dias, os quais acabados atravessão per terra 8 dias athe as cabeceiras do rio Botetey no qual fazem canoas e com ellas descem per espaço de 12 dias ao Paraguay, dahi sobem athe a barra de Tacoary assima 3 dias, e dahi a barra. Parrudos na forma já dita. Este caminho he mais abundante de sustento, mas arricasdo a encontrar tropas de Castelhanos, e Cavalleiros Guaycorús, o qual perigo não tem o caminho do rio Pardo. O Excellmo. Senhor General Rodrigo Cezar e Menezes prohibio per justas causas o caminho pella vacaria, e concordarão os Paulistas em que o caminho geral fosse pello rio Pardo. Outros Paulistas tanto que chegarão ao rio grande descem por este só por tempo de 2 ou 3 dias e chegando a barra do rio verde sobem por elle assima per espaço de 10 ou 12 dias, e chegando ao salto do rio ahi dexão as cancas e seguem o mesmo caminho que os que forão pello rio Pardo já assima dito. Tambem abaxo do rio verde esta outro rio 2 dias de viagem chamado Ypitanga pello qual assima se faz a mesma viagem que pello rio verde. $\mathrm{Na}$ viagem do rio verde ha perigo de gentio Bilrreiro ou Cayepô".

$\mathrm{Na}$ descrição dêstes outros caminhos, bem como nas desvantagens que êles ofereciam quando comparados com a róia PardoCamspoã, aproxima-se imensamente êste roteiro do manuscrito da Biblioteca Nacional publicado por Taunay; as dificuldades que $\circ$ sul de Mato-Grosso oferecia, com os constantes ataques des $\mathrm{Ca}$ telhanos, Guaicurús ou Caiapós (os mesmos Bilreiros) são assinaladas nos dois documentos quase que com as mesmas palavras.

Finalmente, assim conclui o roteiro de Evora:

"O caminho por terra é independente de canoas he de São Paulo a Corocaba 3 dias, de Corocaba a serra de Botycatû 7 dias, dahi ao rio grande 15 ou 20 dias, dahi passado o rio grande vão costeando o rio Pardo e fazendo a viagem que já dissemos no caminho navegavel. Todos estes caminhos que acima ficão ditos levão a frente ja a Oeste, ja a Noroeste, Norte e Nordeste. O caminho de terra pellos Batatais he mais direito e breve, mas por hora impraticavel pello perigo dos Cayapos".

Notável não só neste roteiro, como em todos os demais do sésecuo XVIII a preocupação constante com o indígena. Bilreiro, caiap6, paiaguá, guaicurú são nomes que ocorrem a todo instante. Aliás, contra as agressões dêsses indios, que só diminuiram com o findar do século XVIII, não encontraram os viajantes outro recurso senão navegar sòmente em camboios e com canoas artilhadas. 
Em seu magnífico ensaio "Monções", Sérgio Buarque de Holanda teve ocasião de apreciar devidamente as navegações para Mato-Grosso durante o século XVIII e primeira metade do sé culo XIX, quando desapareceram completamente. As viagens fluviais, já no início do século passado, tornaram-se bastantes raras, devendo-se isto, em grande parte, ao aproveitamento de outras vias, principalmente as do norte do país. Entretanto, segundo observa o ensaista de "Raizes do Brasil", "o aproveitamento dos rios que precuram o oceano no extremo-norte, prende-se ao do velho caminho das monções, que avança do sul, do planalto paulista. A função histórica. dessa autêntica estrada fluvial de perto de dez mil quilômetros, que abraça quase todo o terrioório da América Portuguêsa, supera a de qualquer das outras linhas de circulação natural do Brasil" (10).

O grande papel dessas monções foi, sem dúvida, assinalar e garantir para Portugal (e conseqüentemente para o Brasil) a posse de uma das mais extensas regiões de terras contínuas do globo, firmando a jurisdição portuguêsa de maneira a não deixar dúvida quando, em 1750 , no Tratado de Madrí, fizeram as côrtes portuguêsa valer o princípio do uti-possidetis para a demarcação de suas fronteiras com as colônias espanholas.

ODILON NOGUEIRA DE MATOS

Licenciado em Geografia e Historia (U. S. P.).

(10) - Holanda, Sergio Buarque de: Monçoes, p. 11.1. Lio, Casa do Matudante do Brasil, 1945. 